\title{
Ethics in women's health: A pathway to gender equity
}

\author{
Luciana Caenazzo ${ }^{1^{*}}$, Pamela Tozzo ${ }^{1,2}$, Giovannella Baggio ${ }^{1}$ \\ 1 Department of Molecular Medicine, University of Padua, Padova, Italy 2 Department of Biotechnology and Life Sciences, Insubria \\ University, Varese, Italy
}

\begin{abstract}
The differences between women's and men's experiences of health and illness are well known. Gender-specific medicine needs to restore equilibrium in order to understand the different clinical signs, diagnostic procedures, and therapeutic needs of diseases in men and women. This new dimension of medicine needs investment in research and health policy. If health professionals and healthcare organizations do not systematically take gender differences into account, inequities may arise and endure. Most discussions of gender involving an ethical perspective begin with the argument that women and men should be regarded as being of equal moral value. Where there are no relevant differences between them, then fairness and justice dictate that they should be treated equally, but if differences in needs exist, service planning should take this into account. Under these circumstances, equity as well as equality should be a guiding principle. The promotion of greater equality between men and women has also become a crucial issue in the bioethical debate, even if there is some confusion about the meaning of equality in this context, and especially of how this can be obtained. Biological differences cannot be removed, but their potentially harmful effects can be mitigated through social policies that take them properly into account, and through health research, policies and projects that give due attention to gender considerations and promote gender equity between women and men.
\end{abstract}

Citation: Caenazzo L, Tozzo P, Baggio G(2015) Ethics in women's health: A pathway to gender equity. Advances in Medical Ethics 2:5. doi:10.12715/ame.2015.2.5

Received: February 27, 2015; Accepted: August 13, 2015; Published: November 1, 2015

Copyright: (C) 2015 Caenazzo et al. This is an open access article distributed under the terms of the Creative Commons Attribution License, which permits unrestricted use, distribution, and reproduction in any medium, provided the original work is properly cited.

Competing interests: The authors have declared that no competing interests exist.

*Email: luciana.caenazzo@unipd.it

\section{Introduction}

Gender medicine is the study of the influence of sex (in the biological sense) and of gender (in the social sense) on physiology, pathophysiology and on diseases. It aims at reaching decisions and evidencebased treatments for both men and women, and is concerned with the study of the differences in the medical field, in terms of prevention, clinical manifestations, therapeutic approaches, prognosis, psychological and social impact [1].

The terms 'sex' and 'gender' are often used interchangeably, but the two concepts have different meanings. 'Sex' refers to the biologically determined differences between males and females; a definition that may appear, by means of a superficial interpretation, relatively simple. An individual's sex is represented by complex chromosomal characteristics, internal and external genitalia, hormone balance and secondary sexual characteristics.

The term 'gender', on the other hand, refers more strictly to psychological aspects, social and cultural rights. It involves the circumstances of a person's life, the belief that each person has in him or herself and the behavior that men and women have in the social sphere, how they appear, how they think, what they feel, how they dress and how they perceive the world in which they live.

According to the World Health Organization [2], the term 'gender' should describe those characteristics of women and men that are socially constructed, while the term 'sex' should refer to biologically determined 
aspects. People are born male or female, but learn to be girls and boys, and then grow into women and men. This learned behavior constitutes gender identity and determines social gender roles.

In biomedical sciences, gender medicine implies the study of gender-related differences, not only with regard to anatomical and physiological aspects, as functionality and clinical response to treatments, but also with particular attention to the psychological implications, and to social and cultural rights.

\section{Medical aspects}

The health differences between men and women are well known in the literature, and significant differences exist in mortality and morbidity rates. It is interesting to note that the nature of these gender differences vary between different countries and, within the same country, vary between different regions and different social groups [3, 4].

The distribution of diseases and the related morbidity rate is very variable: it is evident that women are at greater risk for certain transmittable infectious diseases, such as malaria and HIV, or for nontransmittable diseases such as depression, anxiety and arthritis. On the contrary, men have a greater risk of suffering from traumatic injuries and problems related to substance abuse or addiction.

Some examples of how gender medicine applies to clinical practice come from cardiology, oncology and internal medicine $[5,6]$. Women live longer than men, but a greater level of disability often mars the quality of life associated with this greater survival. In addition, over the past 30 years there has been a significant decline in mortality from cardiovascular diseases in men but not in women [1].

In terms of oncological pathologies, women exhibit differences in the effectiveness of drugs related to metabolic diversity, have a different manifestation of symptoms of certain types of cancer with the same histologic features and staging, a different impact of comorbidities, and different consequences of tumors in the relational, social, and familial spheres [7].

Clinical data suggest that men and women show differences in the epidemiology and progression of some diseases, such as liver disease, autoimmune diseases, genetic hemochromatosis, non-alcoholic steatohepatitis, chronic hepatitis $\mathrm{C}$ and osteoporosis $[1,8]$.

Women remain under-represented in Phase 1 and 2 clinical trials. Pharmacokinetic analysis, which is performed during these stages, would be useful to detect potential differences in dosage required to prevent side effects, contributing to greater drug effectiveness in each patient [9]. Consequently, medicine applied to women is less evidence-based than that applied to men. Even the recruitment of women in Phase 3 studies has been poor [10]; however, over the past decade there have been requests from authorities to reduce gender differences in research $[11,12]$.

Possible solutions could arise from requests for justification as to why different numbers of males and females are proposed for these studies, thereby encouraging the publication of studies in which both sexes are adequately represented. In addition, drug agencies should ensure that physicians and patients are aware of the differences between the sexes in terms of dosage and reactions to medications.

An emblematic example of how gender differences affect experimentation in biomedicine is that of clinical studies on the effect of drugs in pregnancy: pregnant women get sick just as sick women get pregnant. To enlist pregnant women in clinical trials is certainly problematic for numerous reasons, but health protection requires the avoidance of situations where, in the absence of information, physicians prescribe drugs to pregnant women while knowing very little or even nothing at all about them, or even not prescribe them at all.

\section{Implications for practice and policy}

The promotion of greater equality between men and women has become a crucial issue not only in the bioethical debate but also in the international sociopolitical field, despite the persistency of confusion about the meaning of the term 'equality' in this context and, more importantly, on how this might be achieved.

'Gender equality' and 'gender equity' are both widely used in literature analyzing gender differences and 
their implications for biomedicine. It is, however, worth pointing out some issues on the difference between the two definitions and their practical implications.

Most discussions of 'gender justice' assume that men and women should be considered of equal moral value, and in this light it is interesting to analyze the position of Payne and Doyal [13]: if one admits that there are no major differences between genders, then respect for the principle of justice should require men and women to be treated equally. This means that men and women should have equal access to the same tools and the same services in all spheres of personal and social life. Therefore, assuming the absence of differences between genders, both equality (equality) and fairness (equity) should be pursued.

However, reflecting on the field of biomedicine, where it is clear there are gender differences of social or biological nature, which affect individuals' ability to protect their health, then any biomedical application that does not take these differences into account would be unfair and certainly productive of inequality. In the area of health, the planning and management of services should take gender differences into account $[14,15]$.

Despite an initial and general preference for the term 'gender equality' in health policy, some international organizations have started to use the term 'gender equity' instead because this expression seems to more properly reflect the importance of biological and social differences in influencing morbidity and mortality in men and women.

The key objective in biomedicine and health programming on a local and global scale is not gender equality per se, but the recognition of the different needs of men's and women's health by virtue of their differences: that is gender equity that should be guaranteed in health policies.

The reason why it seems to be more appropriate - in the context of the management of health policies, unlike other areas - to apply gender equity with respect to gender equality, resides in the inevitable physiological differences between biologically male and biologically female subjects.

Biology and physiology are determining factors in the promotion and protection of health and the lack of recognition of differences can create more inequality between men and women. Of course, biological differences cannot be removed, but their potential harmful effects, for one group over another, can be prevented with health policies that properly take them into account, with a view to equity rather than equality. Moving from this concept, whichever strategy is applied - starting from a condition of equality in gender diversity - an achievable goal in medicine is to ensure that both men and women have the opportunities to maximize their health potential, with respect to their biological diversity, and it is in this context that strategies to achieve a condition of gender equity must take into account differing health needs.

Compared with their mothers, most women today are better educated and participate more consistently in working life. Reflecting on their general state of health, this fact is because of a slow but progressive education towards 'gender sensitivity' (in medicine). In turn, this is owed more to a cultural matrix than to health awareness, but it nevertheless shows that an education spread throughout life and a consequent level of autonomy and self-consciousness is functional to a global process for achieving gender equity.

Life and human health are not only results, but they are first of all of assets. They are not products, but values for the individual and for society. Therefore, in a deontological and ethical sense, the professional responsibility lies not so much with securing a result, but in making a commitment towards an asset such as life and health.

This commitment, in an ethical perspective, is not only a commitment to the means to achieve a goal, but an approach for global benefit; becoming important for all health professions to be aware of the importance of a gender-based approach to medicine, and also in structuring future versions of codes of conduct as an educational tool to raise awareness and knowledge on these issues. Sensitivity towards gender issues, however, is the result of a process of education and health organization, which today is still lacking, and cannot be exhausted only in the ethical debate.

In clinical practice, the recognition of gender medicine implies being formed with a 'gender sensitivity', which is the expertise of health professionals in identifying existing gender 
differences and incorporating these in the decisionmaking process of care and treatment.

\section{Conclusions}

To create sustainable changes that will improve people's health and quality of life, efforts on the part of governmental and non-governmental structures in terms of health programming should be directed towards achieving 'gender equity',

Given the magnitude of the problem, a bioethical discussion on this topic could encourage the pursuit of gender equity in healthcare and promote the full recognition of women's rights to health. This could be one of the most effective and direct ways to reduce inequalities and to ensure a rational and efficient use of resources.

All gender differences, both in clinical and research settings, should be taken into account in the various aspects of health planning, including those related to healthcare professionals' education, as well as education within the general population. The widespread diffusion of what we might call 'gender sensitivity' would, in this way, be structured through healthcare professionals and population education, and through the design and implementation of more adequate healthcare policies, oriented to the pursuit of gender equity.

It is necessary to find models, such as a reference in the healthcare professionals' code of ethics, which could include the above-mentioned considerations. A greater ethical dialogue between professional men and women is important to be of help in the relationship between professionals, and between professionals and patients, on the basis of a relationship typically understood as that between one person and another, in consideration of equalities and differences.

A shared reflection that takes into account not only the biologically and epidemiologically relevant differences among genders, but also the main determinants of health under an ethical perspective, may find a role in a structured education to diversity, sensitivity and gender equity.

\section{References}

1. Baggio G, Corsini A, Floreani A, Giannini S, Zagonel V. Gender medicine: a task for the third millennium. Clin Chem Lab Med. 2013;51:713-27.

2. World Health Organization. WHO gender policy: integrating gender perspectives in the work of WHO. Annex 1 [Internet]. Geneva; 2002 [Cited 2015 Feb 26]. Available from: http://whqlibdoc.who.int/hq/2002/a78322.pdf.

3. Payne S. The health of men and women. Cambridge: Polity Press; 2006.

4. World Health Organization. Life expectancy: life expectancy by country 2011 [Internet]. Geneva; 2011 [Cited 2015 Feb 26]. Available from: http://apps.who.int/gho/data/node.main.688.

5. Bassuk SS, Manson J. Gender-specific aspect of selected coronary heart disease risk factors: a summary of the epidemiologic evidence. In: Legato M, editor. Principles of gender-specific medicine. Amsterdam: Elsevier Academic Press; 2010. p. 162-170.

6. Pal SK, Hurria A. Impact of age, sex and comorbidity on cancer therapy and disease progression. J Clin Oncol. 2010;28:4086-93.

7. Deenen MJ, Cats A, Beijnen JH, Schellens JH. Pharmacogenetic variability in phase II anticancer drug metabolism. Oncologist. 2011;16:992-1005.

8. Geusens $P$, Dinant G. Integrating a gender dimension into osteoporosis and fracture risk research. Gend Med. 2007;4 Suppl B:S147-61.

9. Redberg RF. Don't assume women are the same as men: include them in the trial. Arch Intern Med. 2012;172:921.

10. Franconi F, Brunelleschi S, Steardo L, Cuomo V. Gender differences in drug responses. Pharmacol Res. 2007;55:81-95.

11. Vidaver RM, Lafleur B, Tong C, Bradshaw R, Marts SA. Women subjects in NIH funded clinical research literature: lack of progress in both representation and analysis by sex. J Womens Health Gend Based Med. 2000;9:495-504.

12. European Commission. Research Directorate-Generale. Gender action plan in integrated projects and networks of excellence. Compendium of best practices [Internet]. Brussels; 2004 [Cited 2015 Feb 26]. Available from: http://www.genderkompetenz.info/w/files/gkompzpdf/g apbestpractice_04.pdf.

13. Payne S, Doyal L. Re-visiting gender justice in health and healthcare. In: Kuhlmann E, Annadale E, editors. The Palgrave handbook of gender and healthcare. London: Palgrave Macmillan; 2012. p. 21-35.

14. Doyal L. Putting gender into health and globalization debates: new perspectives and old challenges. Third World Quarterly. 2002;23:233-50. 
15. Jackson BE, Haworth-Brockman MJ. The quality of evidence: enhancing uptake of qualitative evidence for gender equity and health. Int $\mathrm{J}$ Public Health. 2007;52:265-6. 